\title{
The paraoxonase PON1 promoter polymorphism C(-107)T is associated with increased serum glucose concentrations in non-diabetic patients
}

\author{
I. Leviev, B. Kalix, M-Cl. Brulhart Meynet, R. W. James \\ Clinical Diabetes Unit, Division of Endocrinology and Diabetes, University Hospital, Geneva, Switzerland
}

\begin{abstract}
Aims/hypothesis. Oxidative stress could contribute to diabetes and its complications by predisposing to insulin resistance. Lipid peroxidation products are thought to be one mechanism involved in reduced insulin sensitivity. The serum enzyme, paraoxonase-1, protects lipoprotein lipids from oxidation. We examined the hypothesis that paraoxonase- 1 could be associated with abnormal serum glucose concentrations in non-diabetic patients.

Methods. Serum paraoxonase-1 activities and concentrations, as well as paraoxonase- 1 gene polymorphisms, were analysed as a function of fasting glucose concentrations in non-diabetic patients and in Type II (non-insulin-dependent) diabetic patients.

Results. Serum paraoxonase-1 activities and concentrations were lower $(p<0.05)$ in non-diabetic patients with abnormal fasting glucose concentrations. It was due to a higher frequency of low expressor paraoxonase-1 promoter genotypes in patients with
\end{abstract}

abnormal glucose control. Promoter polymorphisms were independent determinants of abnormal fasting glucose concentrations. Low expressor genotypes were associated with higher glucose concentrations in non-diabetic patients $(p=0.046)$ and a trend to higher concentrations in Type II diabetic patients. The coding region paraoxonase-1 polymorphisms L55 M and Q192R was not associated with differences in fasting glucose.

Conclusion/interpretation. The promoter polymorphism C(-107)T is a marker for abnormal fasting glucose concentrations in non-diabetic patients. It could indicate an active role for paraoxonase-1, possibly pre-disposing to insulin resistance, or linkage of paraoxonase-1 polymorphisms with other gene products implicated in glucose metabolism. [Diabetologia (2001) 44: 1177-1183]

Keywords Type II diabetes, oxidative stress, LDL, HDL, diabetic complications, genotype, glucose intolerance.
Studies show an association between diabetes and oxidative stress $[1,2]$. They have highlighted the higher concentrations of oxidation products, notably lipid peroxides, in diabetic patients [3-5]. Mechanisms which promote oxidation due to raised plasma glucose and advanced glycation end-products, have also been explored $[6,7]$. In this context, increases in oxi-

Received: 17 April 2001 and in revised form: 14 May 2001

Corresponding author: Dr. Richard W.James, Clinical Diabetes Unit, Division of Endocrinology and Diabetology, University Hospital, 1211 Geneva 14, Switzerland, E-mail: Richard.James@hcuge.ch

Abbreviations: PON1, paraoxonase-1 dative stress are considered to be a consequence of diabetes, although oxidative stress could also play a causal role in diabetes [2,8]. In vitro studies have shown that oxidative stress can impair the action of insulin on adipocytes [9]. A beneficial impact of anti-oxidant treatment, notably in preserving betacell function [10] has been reported in vivo using $d b$ / $d b$ mice. Lipid oxidation products seem to have a pathological role because they inhibit glucose-induced insulin secretion from rat pancreatic islets [11]. Oxidised low density lipoproteins (LDL) can also impair endothelial function [12]. The impact of oxidative stress on endothelial function is important because endothelial dysfunction could predispose to 
insulin resistance $[13,14,15]$. Thus, increased oxidative stress has been observed in pre-diabetic patients $[16,17]$, as well as obese, non-diabetic patients and could contribute to peripheral insulin resistance $[18$, 20]. Moreover, insulin resistance has been found to determine concentrations of oxidised LDL in non-diabetic individuals [21]. Increased oxidative stress could therefore be a feature of the insulin resistance or metabolic syndrome [21].

Higher concentrations of oxidation products in diabetes could result not only from increases in pro-oxidant factors but also from reductions in the anti-oxidant capacity $[1,14,17,22]$. The HDL-associated enzyme paraoxonase plays a major role in protecting plasma lipoproteins, notably LDL, from oxidation $[23,24]$. Interestingly, serum PON1 activity is reduced in diabetic patients to a point where the capacity of the enzyme to protect LDL from oxidation is affected [25-27]. This could be a consequence, at least in part, of a direct influence of high glucose concentrations on PON1 in overt diabetes [28]. However, because LDL oxidation could be related to insulin resistance in non-diabetic individuals we considered the potential involvement of PON1 [21]. We examined the relation between fasting glucose concentrations, as an indicator of abnormal glucose control, serum paraoxonase values and paraoxonase gene polymorphisms. Our hypothesis was that lower serum PON1 values could be associated with impaired glucose control.

\section{Methods and materials}

Study population. Patients and control subjects were consecutively recruited from those attending the Cardiology Division of the University Hospital, Geneva. They gave their written, informed consent to the study which was done according to the requirements of the Ethics Committee of the medical faculty. All participants underwent a biplane coronary arteriographic examination (standard Judkins technique) and arteriograms were considered positive (coronary artery disease positive $(\mathrm{CAD}+\mathrm{ve}))$ if a stenosis estimated to be $20 \%$ or more was detected in one major epicardial vessels. The CAD-ve group was composed of subjects with no detectable stenosis in any artery and with no evidence of myocardial infarction. The cohort, recruited for studies of genetic risk factors for atherosclerotic disease, consisted of $547(70.2 \%$ men $)$ non-diabetic patients, $118(80.5 \%$ men $)$ patients with abnormal fasting glucose and 150 (74.5\% men) patients with Type II (non-insulindependent) diabetes mellitus. A fasting blood sample was obtained after an overnight stay in the hospital and patients completed detailed questionnaires on lifestyle as well as personnel and family medical histories with an interviewer.

Patients with Type I (insulin-dependent) diabetes were excluded from the study. Diabetes was established from questionnaires and confirmed by the patient's medical file and the use of diabetic medication. Patients without an indication of diabetes but with fasting plasma glucose concentrations of $6.1 \mathrm{mmol} / \mathrm{l}$ or more were assigned to the abnormal glucose control group (according to WHO criteria [30]). Patients with fasting blood glucose concentration above $7.0 \mathrm{mmol} / \mathrm{l}$ were classified as diabetic patients.
Laboratory techniques. Plasma lipid, lipoprotein and apolipoprotein concentrations, as well as glucose concentrations were analysed [29]. Paraoxonase serum activities and concentrations were assayed [31] and gene polymorphisms affecting coding and promoter regions were determined by restriction isotyping and allele specific hybridisation $[32,33]$.

Statistical analysis. Differences between continuous variables were analysed by ANOVA; categorised variables were analysed by the chi square $\left(\chi^{2}\right)$ test. Logistic regression analysis was used to assess associations with fasting glucose, where abnormal fasting glucose was the dependent variable and potential determinants the independent variables. Significance was tested by the Wald test.

\section{Results}

Patients with abnormal fasting glucose had significantly higher BMI and systolic blood pressure (despite a large percentage of patients under treatment), were older and had a greater frequency of coronary artery disease than patients with normal fasting glucose concentration (Table 1). Male patients were more frequent in the abnormal group. There was a trend to higher triglycerides and lower HDL-cholesterol. Cholesterol concentrations were similar. PON1 activities and concentrations were significantly lower in the abnormal glucose group (Table 1).

Several coding region and promoter polymorphisms have been identified in the PON1 gene and these can affect serum concentrations and activities of the enzyme [32-35]. Figure 1 shows the genotype frequencies for the promoter $\mathrm{C}(-107) \mathrm{T}$ and coding region Q192R and L55 M polymorphisms. There was a higher frequency of the low expressor TT genotype [33] in the abnormal (non-diabetic) glucose group compared with the normal glucose group $(p<0.02$ for genotype and $p<0.03$ for alleles). No association was observed between the presence of glucose abnormalities and the 192 or 55 polymorphic sites (Fig. 1), although there was a non-significant trend to a lower frequency of the MM genotype (polymorphism 55) in the abnormal group $(p=0.13$ for $\mathrm{MM} \mathrm{v}$ $\mathrm{ML}+\mathrm{LL})$. We observed in previous studies a linkage disequilibrium between the M55 allele and the low expressor promoter genotype [33].

Determinants of abnormal fasting glucose were analysed in the combined cohort by logistic regression analysis. The promoter polymorphism emerged as an independent determinant of abnormal glucose values, together with hypertension, gender and age (Table 2). Of note, abnormal glucose concentrations were independent of cardiovascular status and lipid concentrations. Furthermore, when glucose concentrations were analysed as a continuous variable by stepwise regression analysis, the promoter polymorphism was also an independent determinant of glucose values $(p=0.027)$, together with BMI 
Table 1. Clinical characteristics of participants with normal and abnormal fasting plasma glucose values

\begin{tabular}{|c|c|c|c|}
\hline Parameter & Normal & Abnormal & $p$ (ANOVA) \\
\hline$n(\mathrm{M} / \mathrm{F})$ & $547(384 / 163)$ & $118(95 / 23)$ & 0.01 \\
\hline Age (years) & $58.9 \pm 10.3$ & $62.5 \pm 9.4$ & $<0.001$ \\
\hline BMI & $26.5 \pm 3.9$ & $27.9 \pm 4.5$ & $<0.01$ \\
\hline Triglycerides (mmol/l) & $1.49 \pm 0.99$ & $1.62 \pm 0.90$ & ns \\
\hline HDL-chol (mmol/l) & $1.20 \pm 0.34$ & $1.15 \pm 0.32$ & ns \\
\hline Apo B $(\mathrm{g} / \mathrm{l})$ & $0.96 \pm 0.23$ & $0.98 \pm 0.21$ & ns \\
\hline $\mathrm{BP}$ (systolic) & $130.0 \pm 17.5$ & $134.1 \pm 19.5$ & 0.027 \\
\hline BP (diastolic) & $79.3 \pm 11.1$ & $78.5 \pm 13.2$ & ns \\
\hline Smoker/ex-smoker (\%) & 71.9 & 77.1 & ns \\
\hline CAD + ve (\%) & 73.1 & 83.9 & 0.01 \\
\hline PON activity $(\mathrm{U} / \mathrm{ml})^{\mathrm{a}}$ & $84.1 \pm 28.8$ & $78.3 \pm 20.3$ & 0.047 \\
\hline PON activity $(\mathrm{U} / \mathrm{ml})^{\mathrm{b}}$ & $265.1 \pm 181.8$ & $230.0 \pm 145.3$ & 0.05 \\
\hline PON mass $(\mu \mathrm{g} / \mathrm{ml})$ & $97.7 \pm 21.8$ & $90.9 \pm 21.3$ & $<0.01$ \\
\hline
\end{tabular}

* Ns, not significant at $p=0.05$

${ }^{\mathrm{b}}$ Activity assayed with phenylacetate as substrate

Type I and II diabetic patients were excluded. Values are means \pm SD

${ }^{\mathrm{c}}$ Activity assayed with paraoxon as substrate

Table 2. Determinants of abnormal fasting glucose categories

\begin{tabular}{lcl}
\hline Parameter & $\chi^{2}$ Values & $p$ \\
\hline Hypertension & 10.80 & 0.001 \\
Age & 9.41 & 0.002 \\
Polymorphism C(-107)T & 7.81 & 0.02 \\
Gender & 4.58 & 0.03 \\
BMI & 3.15 & 0.07 \\
\hline
\end{tabular}

The dependent variable was fasting glucose $(0$, normal; 1 , abnormal). The following were also tested in the model but gave $p$ values $>0.10$; Triglycerides, HDL-cholesterol, cholesterol, smoking status, CHD status, PON1 genotypes 192 and 55

$(p<0.001)$, CHD status $(p<0.001)$, age $(p=0.001)$ and hypertension $(p=0.036)$.

Fasting glucose concentrations were then analysed as a function of the promoter and coding region genotypes in the total cohort. Glucose concentrations levels differed significantly between the promoter genotypes, being higher for the TT homozygote (low expressor) (Table 3). There was no association between the Q192R and L55 M genotypes and serum glucose concentrations, although there was a trend to higher concentrations in MM homozygotes (Table 3; MM v $\mathrm{LM}+\mathrm{LL}, 5.52 \pm 0.72 \mathrm{mmol} / \mathrm{l}$ vs $5.38 \pm 0.70 \mathrm{mmol} / \mathrm{l}$; $p=0.09)$. When Type II diabetic patients were analysed, there was a non-significant trend to increased glucose values in the TT homozygotes (CC v CT v TT; $8.5 \pm 2.2$ v $8.5 \pm 2.9$ v $9.3 \pm 2.7 \mathrm{mmol} / 1 ; p=0.33$ and $p=0.14$ for $(\mathrm{CC}+\mathrm{CT}) \mathrm{v}$ TT $)$.

\section{Discussion}

We found an association between reduced concentrations and activities of the anti-oxidant enzyme PON1 and disturbed glucose control. We also ob- served an increased frequency of low expressor PON1 promoter genotypes in patients with abnormal fasting serum glucose. Genotype distribution seems to account for the lower values of PON1 in the abnormal glucose group. Fasting glucose concentrations were significantly higher in non-diabetic patients who were homozygous for the low expressor, promoter genotype. We also found a trend to higher concentrations in Type II diabetic patients who were under hypoglycaemic treatment. In this cohort the promoter polymorphism C(-107)T therefore seemed to be a marker for abnormal glucose control.

The lower serum activities and concentrations of PON1 in patients with serum glucose abnormalities seem to be a consequence of the modified distribution of promoter genotypes. We have shown that the promoter polymorphism C(-107)T has an important influence on gene expression and serum values of PON1 [33]. The promoter polymorphism was a stronger determinant than PON1 activity and concentration of glucose abnormalities according to multivariate analyses. Glycosylation is thought to influence serum PON1 [28] and lower serum PON1 has been reported in diabetic patients [25-27]. However, we also observed lower concentrations of PON1 in non-diabetic patients, although some of the latter were glucose-intolerant. Stepwise regression analyses with serum PON1 concentration as the dependent variable showed the association with fasting glucose values to be of borderline significance $(p=0.063)$ when diabetic patients were included. The association was lost when diabetic patients were removed (results not shown). The major determinant of serum PON1 concentration was the promoter polymorphism $(p<0.001 ; 19.9 \%$ of variation in concentration, corresponding to our previous studies [33]). 

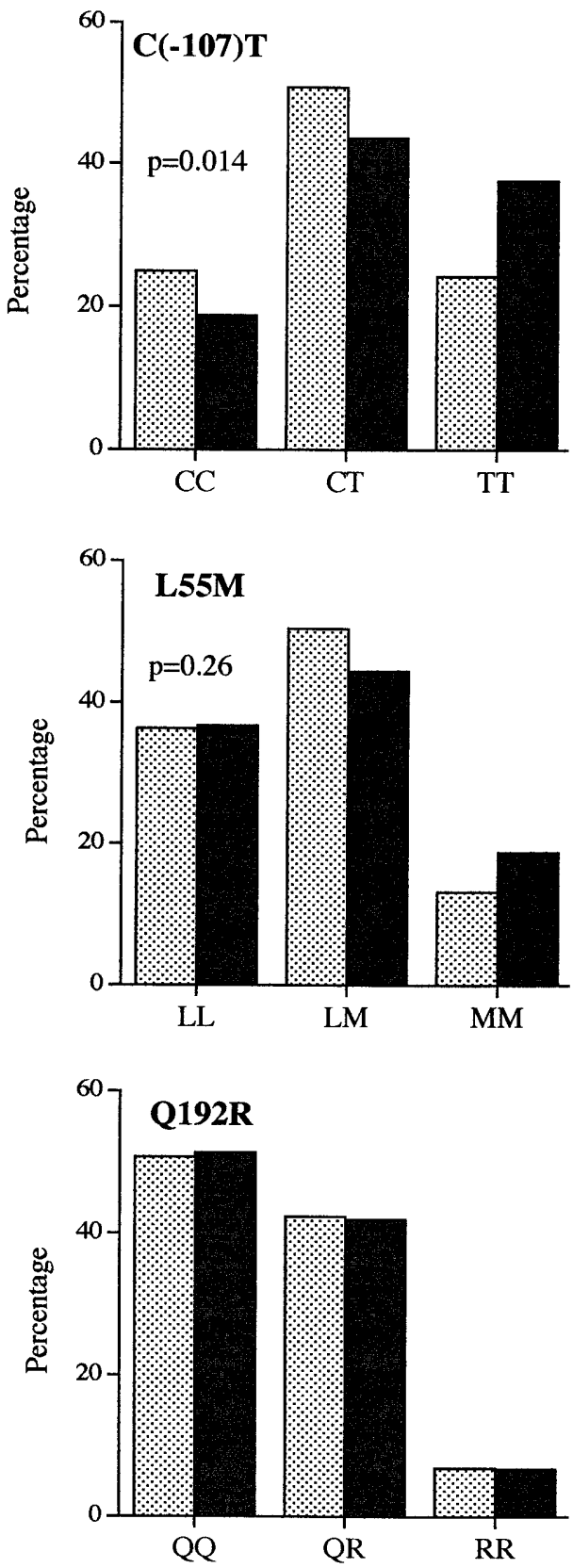

Fig. 1. Distributions of genotypes arising from promoter $(\mathrm{C}$ $(-107) \mathrm{T})(p=0.014)$ and coding region L55 M $(p=0.26)$ and Q192R $(p=0.99)$ polymorphisms of the PON1 gene in nondiabetic patients with normal $(<6.1 \mathrm{mmol} / \mathrm{l})$ and abnormal ( $\geq 6.1 \mathrm{mmol} / \mathrm{l}$ ) fasting plasma glucose values. Normal (퓨); Abnormal (ם)

Even quantitatively small changes in serum PON1 modulate the anti-oxidant capacity of HDL [27]. Moreover, such modifications should be considered in the physiological context of atherosclerosis as a slowly evolving, chronic disease and the greater degree of oxidative stress to which diabetic patients are subject.

The increased frequency of low expressor promoter genotypes is interesting in the context of the anti-oxidant function of PON1, protecting in particular serum lipids and lipoproteins from oxidation $[36,37]$. Lower serum concentrations of PON1 have been associated with increased lipid oxidation, i.e. greater oxidative stress, in animal models [38,39] and human beings [24]. An increased predisposition to oxidative stress could therefore be one consequence of low expressor PON1 genotypes. Oxidative stress is thought to be a consequence $[6,7]$ and a potential cause of diabetes and diabetic complications, in part by predisposing to insulin resistance $[2,8]$. Endothelial function is particularly susceptible to oxidative stress and insulin resistance could be one consequence of endothelial dysfunction [20]. Moreover, oxidised LDL induces endothelial dysfunction and one of the principal functions of PON1 is to prevent LDL oxidation. Studies have indicated other pathways, also involving lipid peroxidation products, by which oxidative stress could impair insulin action $[9,10,40]$. Thus, there are several possible mechanisms by which a modified, anti-oxidant capacity of PON1 could contribute to reduced insulin sensitivity.

An alternative explanation is that PON1 polymorphisms could be in linkage disequilibrium with other genes related to insulin resistance. The region of chromosome 7 containing the $P O N$ gene family is a susceptibility locus for insulin resistance, albeit in a particular ethnic group, Pima Indians [41].

Studies indicate an association between PON1 polymorphisms and various diabetic complications, notably coronary disease (which seems to be more frequent in diabetic [42-47] than in non-diabetic populations [48-54]) as well as retinopathy [55,56], neuropathy [25] and nephropathy [57,58]. Our study suggests PON1 polymorphisms could reflect, and possibly contribute to abnormal glucose control and hence insulin resistance, a risk factor for these complications. A recent study showed PON1 genotypes (of the Q192R polymorphism) to be associated with endothelial dysfunction in coronary patients [59].

Before drawing conclusions, it is important to consider that abnormal glucose control was established from fasting glucose values; an oral glucose tolerance test was not undertaken. It should be noted, however, that glucose values were established after an overnight stay in hospital, ensuring a 12-h fast. Insulin resistance was not measured (e.g. using the HOMA method) and inferences concerning insulin sensitivity were made from abnormal fasting glucose. Finally, patients were recruited in the context of a study of risk factors for coronary disease. PON1 has been identified in some studies as a genetic risk factor for vascular disease. However, regression analyses confirmed that the association of promoter genotypes with glucose abnormalities was independent of vascular status. Of note, a study noted that glycaemic control (haemoglobin $A_{1 c}$ ) was significantly worse in 
Table 3. Fasting glucose concentrations as a function of $P O N 1$ genotypes

\begin{tabular}{lllll}
\hline & Genotype & & \multicolumn{1}{c}{ ANOVA } \\
\hline Promoter C(-107)T & CC (158) & CT (330) & TT (177) & \\
& $5.35 \pm 0.64$ & $5.37 \pm 0.71$ & $5.51 \pm 0.73$ & 0.046 \\
Coding region L55 M & LL (242) & LM (328) & MM (95) & \\
& $5.42 \pm 0.68$ & $5.39 \pm 0.71$ & $5.52 \pm 0.72$ & 0.13 \\
Coding region Q192R & QQ (339) & QR (280) & RR (46) & \\
& $5.39 \pm 0.71$ & $5.41 \pm 0.69$ & $5.46 \pm 0.74$ & 0.76 \\
\hline
\end{tabular}

Number of patients for each genotype group are given in parentheses

Type II diabetic patients with retinopathy who were carriers of the M55 allele compared to non-carriers (LL55 homozygotes) with retinopathy [60]. We found a non-significant trend to higher glucose concentrations in MM homozygotes and, as mentioned previously, we first reported a linkage disequilibrium between the coding region M55 allele and the T allele of the promoter $\mathrm{C}(-107) \mathrm{T}$ polymorphism [33]. Although promoter genotypes were not analysed in the study [60], we reported linkage disequilibrium between the coding region M55 allele and the T allele of the promoter $\mathrm{C}(-107) \mathrm{T}$ polymorphism [33], and in this study there was a trend to higher glucose concentrations in MM homozygotes.

In conclusion, lower serum values of the anti-oxidant enzyme PON1 are associated with abnormal plasma glucose concentrations. The reductions of serum PON1 seem to be genetically determined as they are linked to promoter polymorphisms with a strong influence on gene expression. Further studies are necessary to examine whether PON1 has a casual role in promoting higher glucose concentrations, perhaps linked to increased risk of defective insulin action by the agency of greater oxidative stress. Alternatively there could be an association of the PON1 promoter polymorphism with insulin resistance susceptibility genes located on chromosome 7 . The study suggests a mechanism which could explain the involvement of PON1 in various complications of diabetes.

Acknowledgements. Particular thanks to Professor A. Righetti (Cardiology Division) for his help and advice during the study and to the nursing staff of the Cardiology Division. We are also grateful to Professor A. Morabia (Clinical Epidemiology Division) for advice on statistical analyses. The technical expertise of S. Bioletto is gratefully acknowledged. The study was supported by grants from the Swiss National Research Foundation (Nos 32-043088-95 and 3100-053731.98), the Swiss Cardiology Society, the Stanley Thomas Johnson Foundation and the Gustave Prévot Foundation.

\section{References}

1. Baynes JW, Thorpe SR (1999) Role of oxidative stress in diabetic complications: a new perspective on an old paradigm. Diabetes 48: 1-9
2. West IC (2000) Radicals and oxidative stress in diabetes. Diabet Med 17: 171-80

3. Lyons TJ (1992) Oxidised low density lipoproteins: a role in the pathogenesis of atherosclerosis in diabetes. Diabet Med 8: 411-9

4. Altomare E, Vendemiale G, Chicco D, Procacci V, Cirelli F (1992) Increased lipid peroxidation in type 2 poorly controlled diabetic patients. Diabetes Metab 18: 264-271

5. Nourooz-Zadeh J, Tajaddini-Sarmadi J, McCarthy S, Betteridge DJ, Wolff SP (1995) Elevated levels of authentic plasma hydroperoxides in NIDDM. Diabetes 44: $1054-1058$

6. Hunt JV, Smith CCT, Wolff SP (1990) Auto-oxidative glycosylation and possible involvement of peroxides and free radicals in LDL modification by glucose. Diabetes 39: 1420-1424

7. Bucala R, Makita Z, Koschinsky T, Cerami A, Vlassara H (1993) Lipid advanced glycosylation: pathway for lipid oxidation in vitro. Proc Natl Acad Sci USA 90: 6434-6438

8. Tooke JE (2000) Possible pathophysiological mechanisms for diabetic angiopathy in type 2 diabetes. J Diabetes Complications 14: 197-200

9. Rudich A, Kozlovsky N, Potashnik R, Bashan N (1997) Oxidant stress reduces insulin responsiveness in 3T3-L1 adipocytes. Am J Physiol 272: E935-E940

10. Kaneto H, Kajimoto Y, Miyagawa J et al. (1999) Beneficial effects of antioxidants in diabetes: possible protection of pancreatic beta-cells against glucose toxicity. Diabetes 48 : 2398-2406

11. Miwa I, Ichimura N, Sugiura M, Hamada Y, Taniguchi S (2000) Inhibition of glucose-induced insulin secretion by 4-hydroxy-2-nonenal and other lipid peroxidation products. Endocrinology 141: 2767-2772

12. Tanner FC, Noll G, Boulanger CM, Luscher TF (1991) Oxidized low density lipoproteins inhibit relaxations of porcine coronary arteries. Role of scavenger receptor and endothelium-derived nitric oxide. Circulation 83: 2012-2020

13. Ting HH, Timimi FK, Boles KS, Creager SJ, Ganz P, Creager MA (1996) Vitamin C improves endothelium-dependent vasodilation in patients with non-insulin-dependent diabetes mellitus. J Clin Invest 97: 22-28

14. Laight DW, Carrier MJ, Anggard EE (2000) Antioxidants, diabetes and endothelial dysfunction. Cardiovasc Res: 457-464

15. Baron AD (1996) The coupling of glucose metabolism and perfusion in human skeletal muscle. The potential role of endothelium-derived nitric oxide. Diabetes 45:[Suppl 1]:S105-5109

16. Salonen JT, Nyyssonen K, Tuomainen TP et al. (1995) Increased risk of non-insulin dependent diabetes mellitus at low plasma vitamin E concentrations: a four year follow up study in men. BMJ 28: 1124-1127 
17. Ford ES, Will JC, Bowman BA, Narayan KM (1999) Diabetes mellitus and serum carotenoids: findings from the Third National Health and Nutrition Examination Survey. Am J Epidemiol 149: 168-176

18. Van Gaal LF, Zhang A, Steijaert MM, De Leeuw IH (1995) Human obesity: from lipid abnormalities to lipid oxidation. Int J Obes 19 [Suppl 3]:S21-S26

19. Tack CJ, Smits P, Demacker PN, Stalenhoef AF (1998) Troglitazone decreases the proportion of small, dense LDL and increases the resistance of LDL to oxidation in obese subjects. Diabetes Care 21: 796-799

20. Pinkney JH, Stehouwer CD, Coppack SW, Yudkin JS (1997) Endothelial dysfunction: cause of the insulin resistance syndrome. Diabetes 46 [Suppl 2]:S9-S13

21. Carantoni M, Abbasi F, Warmerdam F et al. (1998) Relationship between insulin resistance and partially oxidised LDL particles in healthy, nondiabetic volunteers. Arterioscler Thromb Vasc Biol 18: 762-767

22. Ceriello A, Bortolotti N, Falleti E, et al. (1997) Total radical-trapping antioxidant parameter in NIDDM patients. Diabetes Care 20: 194-197

23. Mackness MI, Arrol S, Abbot C, Durrington PN (1993) Protection of low-density lipoprotein against oxidative modification by high-density lipoprotein associated paraoxonase. Atherosclerosis 104: 129-135

24. Aviram M, Rosenblat M, Bisgaier CL, Newton RS, PrimoParma SL, La Du BN (1998) Paraoxonase inhibits highdensity lipoprotein oxidation and preserves its functions. A possible peroxidative role for paraoxonase. J Clin Invest 101: $1581-1590$

25. Abbott CA, Mackness MI, Kumar S, Boulton AJ, Durrington PN (1995) Serum paraoxonase activity, concentration, and phenotype distribution in diabetes mellitus and its relationship to serum lipids and lipoproteins. Arterioscler Thromb Vasc Biol 15: 1812-1818

26. Inoue M, Suehiro T, Nakamura T, Ikeda Y, Kumon Y, Hashimoto K (2000) Serum arylesterase/diazoxonase activity and genetic polymorphisms in patients with type 2 diabetes. Metabolism 49: 1400-1405

27. Boemi M, Leviev I, Sirolla C, Pieri C, Marra M, James RW (2001) Serum paraoxonase is reduced in type 1 diabetic patients compared to non-diabetic, first degree relatives; influence on the ability of HDL to protect LDL from oxidation. Atherosclerosis 155: 229-235

28. Hedrick CC, Thorpe SR, Fu MX et al. (2000) Glycation impairs high-density lipoprotein function. Diabetologia 43: 312-320

29. James RW, Leviev I, Righetti A (2000) Smoking is associated with reduced serum paraoxonase activity and concentration in coronary artery disease patients. Circulation 101: 2252-2257

30. World Health Organisation (1999) Definition, dianosis and classification of diabetes mellitus and its complications: Report of a WHO consultation. Part 1. World Health Organisation, Geneva

31. Blatter Garin M-C, Abbot C, Messmer S et al. (1994) Quantification of human serum paraoxonase by enzymelinked immunoassay: population differences in protein concentrations. Biochem J 304: 549-554

32. Blatter Garin M-C, James RW, Dussoix P et al. (1997) Paraoxonase polymorphism Met-Leu54 is associated with modified serum concentrations of the enzyme. A possible link between the paraoxonase gene and increased risk of cardiovascular disease in diabetes. J Clin Invest 99: 62-66

33. Leviev I, James RW (2000) Promoter polymorphisms of the human paraoxonase PON1 gene and serum paraoxon- ase activities and concentrations. Arterioscler Thromb Vasc Biol 20: 516-521

34. Humbert R, Adler DA, Disteche CM, Hassett C, Omiecinski CJ, Furlong CE (1993) The molecular basis of the human serum paraoxonase activity polymorphism. Nat Genet 3: $73-76$

35. Adkins S, Gan KN, Mody M, La Du BN (1993) Molecular basis for the polymorphic forms of human serum paraoxonase/arylesterase: glutamine or arginine at position 191, for the respective A or B allozymes. Am J Hum Genet 52: 598-608

36. Mackness MI, Arrol S, Durrington PN (1991) Paraoxonase prevents accumulation of lipoperoxides in low-density lipoprotein. FEBS Lett 286: 152-154

37. Cao H, Girard-Globa A, Berthezene F, Moulin P (1999) Paraoxonase protection of LDL against peroxidation is independent of its esterase activity towards paraoxon and is unaffected by the Q-R genetic polymorphism. J Lipid Res 40: 133-139

38. Shih DM, Gu L, Xia Y-R et al. (1998) Mice lacking serum paraoxonase are susceptible to organophosphate toxicity and atherosclerosis. Nature 394: 284-287

39. Shih DM, Xia YR, Wang XP et al. (2000) Combined serum paraoxonase knockout/apolipoprotein E knockout mice exhibit increased lipoprotein oxidation and atherosclerosis. J Biol Chem 275: 17527-17535

40. Yasunari K, Kohno M, Kano H, Yokokawa K, Minami M, Yoshikawa J (1999) Antioxidants improve impaired insulin-mediated glucose uptake and prevent migration and proliferation of cultured rabbit coronary smooth muscle cells induced by high glucose. Circulation 99: 1370-1378

41. Mochizuki H, Scherer SW, Xi T, et al. (1998) Human PON2 gene at 7q21.3: cloning, multiple mRNA forms, and missense polymorphisms in the coding sequence. Gene 213: 149-157

42. Ruiz J, Blanché H, James RW et al. (1995) The polymorphism (Gln-Arg192) of the high-density lipoprotein-bound enzyme paraoxonase is an independent cardiovascular risk factor in non-insulin dependent diabetic patients. Lancet 346: 869-872

43. Odawara M, Tachi Y, Yamashita K (1997) Paraoxonase polymorphism (Gln192-Arg) is associated with coronary heart disease in Japanese noninsulin-dependent diabetic patients. J Clin Endocrinol Metab 82: 2257-2260

44. Pfohl M, Koch M, Enderle MD et al. (1999) Paraoxonase $192 \mathrm{Gln} / \mathrm{Arg}$ gene polymorphism, coronary artery disease, and myocardial infarction in type 2 diabetes. Diabetes 48: 623-627

45. Aubo C, Senti M, Marrugat J et al. (2000) Risk of myocardial infarction associated with Gln/Arg 192 polymorphism in the human paraoxonase gene and diabetes mellitus. The REGICOR Investigators. Eur Heart J 21: 33-38

46. Heijmans BT, Westendorp RG, Lagaay AM, Knook DL, Kluft C, Slagboom PE (2000) Common paraoxonase gene variants, mortality risk and fatal cardiovascular events in elderly subjects. Atherosclerosis 149: 91-97

47. James RW, Leviev I, Ruiz J, Passa P, Froguel P, Garin M-C (2000) The promoter polymorphism T(-107)C of the paraoxonase PON1 gene is a risk factor for coronary heart disease in type 2 patients. Diabetes 49: 1390-1393

48. Serrato M, Marian AJ (1995) A variant of human paraoxonase/arylesterase (HUMPONA) gene is a risk factor for coronary heart disease. J Clin Invest 96: 3005-3008

49. Zama T, Murata M, Matsubara Y et al. (1997) A ${ }^{192} \mathrm{Arg}$ variant of the human paraoxonase (HUMPONA) gene polymorphism is associated with an increased risk for coro- 
nary artery disease in the Japanese. Arterioscler Thromb Vasc Biol 17: 3565-3569

50. Sanghera DK, Saha N, Aston CE, Kamboh MI (1997) Genetic polymorphisms of paraoxonase and the risk of coronary heart disease. Arterioscler Thromb Vasc Biol 17: 1067-1073

51. Imai Y, Morita H, Kurihara H et al. (2000) Evidence for association between paraoxonase gene polymorphisms and atherosclerotic diseases. Atherosclerosis 149: 435-442

52. Antikainen M, Murtomaki S, Syvänne M et al. (1996) The Gln-Arg191 polymorphism of the human paraoxonase gene (HUMPONA) is not associated with risk of coronary artery disease in Finns. J Clin Invest 98: 883-885

53. Herrmann S-M, Blanc H, Poirier O et al. (1996) The Gln/ Arg polymorphism of human paraoxonase (PON 192) is not related to myocardial infarction in the ECTIM study. Atherosclerosis 126: 299-304

54. Gardemann A, Philipp M, Hess K, Katz N, Tillmanns H, Haberbosch W (2000) The paraoxonase leu-Met54 and gln-Arg191 gene polymorphisms are not associated with the risk of coronary heart disease. Atherosclerosis 152: $421-431$
55. Murata M, Nakagawa M, Takahashi S (1998) Molecular variant of the human paraoxonase/arylesterase gene is associated with central retinal vein occlusion in the Japanese population. Ophthalmologica 212: 257-259

56. Ikeda Y, Suehiro T, Inoue M et al. (1998) Serum paraoxonase activity and its relationship to diabetic complications in patients with non-insulin-dependent diabetes mellitus. Metabolism 47: 598-602

57. Dantoine TF, Debord J, Charmes JP et al. (1998) Decrease of serum paraoxonase activity in chronic renal failure. J Am Soc Nephrol 9: 2082-2088

58. Paragh G, Seres I, Balogh Z et al. (1998) The serum paraoxonase activity in patients with chronic renal failure and hyperlipidemia. Nephron 80: 166-170

59. Bauters C, Amant C, Boullier A et al. (2000) Paraoxonase polymorphism (Gln192Arg) as a determinant of the response of human coronary arteries to serotonin. Circulation 101: 740-743

60. Mackness B, Durrington PN, Abuashia B, Boulton AJ, Mackness MI (2000) Low paraoxonase activity in type II diabetes mellitus complicated by retinopathy. Clin Sci (Colch) 98: 355-363 